\title{
CISTO DERMÓIDE CEREBELAR
}

\author{
Walter Pereira * \\ Rolando A. Tenuto ** \\ JAYME WAINMAN ***
}

Os cistos dermóides são raros no sistema nervoso, sua sede mais comum é a raqueana coexistindo, muitas vêzes, com disrafias. Recentemente Canelas e col. 2 referiram dois casos, um com localização intrarraquena e outro diplóico, na região occipital. Cushing, citado por Brock e Klenke ${ }^{1}$, em 1936 tumores do sistema nervoso encontrou apenas três cistos dermóides, um dos quais situado na linha média da fossa posterior. Brock e Klenke ${ }^{1}$ revendo 450 tumores do sistema nervoso registrados no Instituto Neurológico de Nova York até 1931, encontraram apenas dois cistos dermóides, referindo mais um localizado no vermis cerebelar. Love e Kernohan ${ }^{4}$ coletaram no material da Clínica Mayo até 1936, cinco casos, sendo quatro com localização intracraniana e um intrarraqueano. Keville e Wise ${ }^{3}$ em 1959, encontraram apenas dois cistos dermóides nos casos registrados no Centro Médico da Universidade da Califórnia e no "Veteran's Administration Hospital" de São Francisco.

$\mathrm{Na}$ Clínica Neurológica do Hospital das Clínicas da Faculdade de Medicina da Universidade de São Paulo, durante o período de janeiro de 1945 a março de 1963, foram operados 513 tumores intracranianos, dos quais 169 na fossa craniana posterior, sendo encontrado apenas um cisto dermóide, motivo desta publicação.

E. G. P., sexo feminino, 4 anos de idade, branca, registro H.G. 639071. Quadro clinico iniciado dois meses antes da internação com sintomas de hipertensão intracraniana e de comprometimento cerebelar, principalmente vermiano. Exame cliniconeurológico - Criança em bom estado geral, desenvolvimento somático de acôrao com a idade, afebril, consciente e orientada. Perimetro craniano 51 cm; som cle "pote rachado" à percussão do crânio; nenhum déficit motor; coordenação normal nos membros superiores e discretamente alterada, com erros de medida, nos membros inferiores; edema bilateral das papilas ópticas. O exame dos demais aparelhos e sistemas nada mostrou digno de nota. Exames complementares - Craniograma: disjunçāo de suturas. Eletrencefalograma: anormalidade frontal esquerda caracterizada por frequientes ondas delta. Reaçio de Weimberg no sangue: negativa. Ca-

Trabalho da Clinica Neurológica (Prof. Adherbal Tolosa) e do Departamento de Anatomia Patológica (Prof. Constantino Mignone) da Faculdade de Medicina da Universidade de São Paulo, apresentado na 1." Reuniāo da Academia Brasileira de Neurologia (Curitiba, julho de 1963): * Neurocirurgião do Pronto Socorro do Hospital das Clínicas; * Neurocirurgião-chefe; ***Assitente do Departamento de Anatomia Patológica. 
rotidoangiografia esquerda: sinais indiretos de dilatação ventricular. Iodoventriculografia: quadro de processo expansivo cerebelar mediano. Não foi possivel obter líquido cefalorraqueano mediante punção suboccipital.

Com o diagnóstico de provável meduloblastoma cerebelar foi feita a abertura da lâmina terminal para diminuir a hipertensāo intracraniana e, ulteriormente, cobaltoterapia dirigida inicialmente à fossa craniana posterior e, em seguida, ao canal raqueano para destruiçāo de eventuais metástases. Entretanto, ao contrário do que sucede nos casos de meduloblastoma, houve apenas discreta melhora do quadro de hipertensão intracraniana, permanecendo inalterado o quadro cerebelar. Pôsto em dúvida o primeiro dỉagnóstico, cogitava-se da intervençāo direta na fossa posterior quando se instalou, no retalho da craniotomia, processo supurativo que, apesar do tratamento antibiótico local e geral, evoluiu para osteomielite, sendo necessária intervenção cirúrgica para a retirada do osso comprometido. Após esta operação sobrevieram hipertermia e convulsões generalizadas rebeldes a todo tratamento, ocorrendo o óbito 8 dias depois.

Necropsia - Meningite purulenta. No hemisfério cerebelar direito, formação cistica multilobular medindo $7 \mathrm{~cm}$ no seu maior diâmetro com paredes bem delimitadas e de consistência fibrosa, firme e elástica; dentro do cisto foi encontrado material sebáceo com alguns pêlos; o tumor deslocava a cavidade do IV ventrículo para a frente, obliterando parcialmente a cavidade ventricular (Fig. 1). Exame histológico: cisto dermóide multilobular, constituido por espêssa parede de tecido conjuntivo-fibroso e grande número de glândulas sebáceas; o cisto determinava compressão do tecido cerebelar adjacente que se encontrava atrofiado, com intensa gliose reacional (Fig. 2).

\section{RESUMO}

Os autores relatam um caso de cisto dermóide cerebelar, único encontrado entre 513 tumores intracranianos operados de janeiro de 1945 a março de 1963, confirmando sua raridade. Tratava-se de criança que apresentava

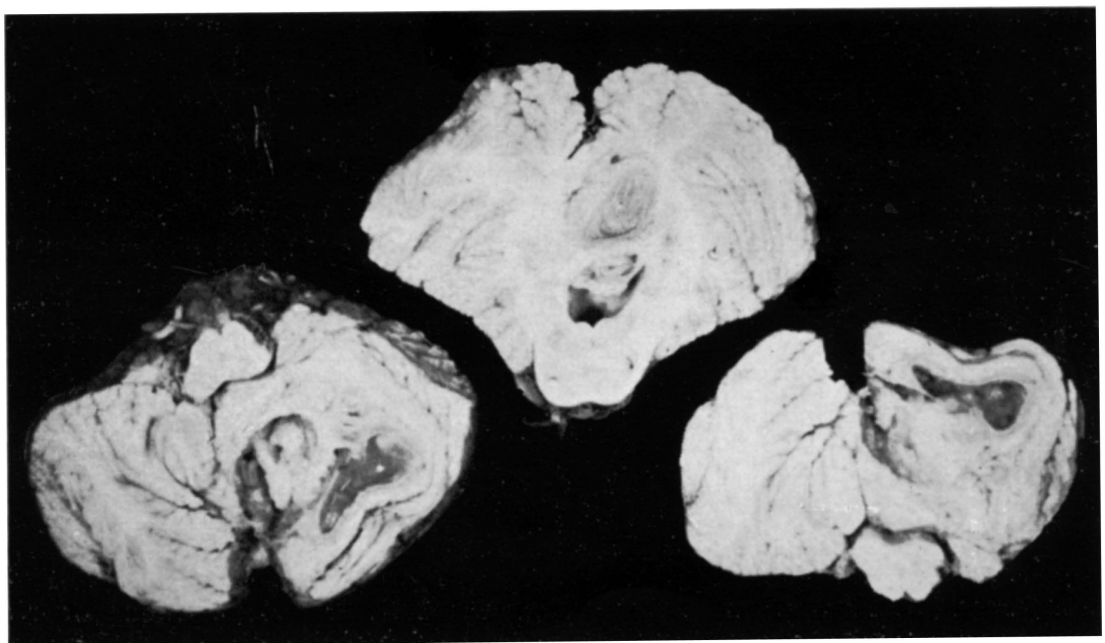

Fig. 1 - Caso E. G. P. Cisto dermóide no hemisfério cerebelar direito. 

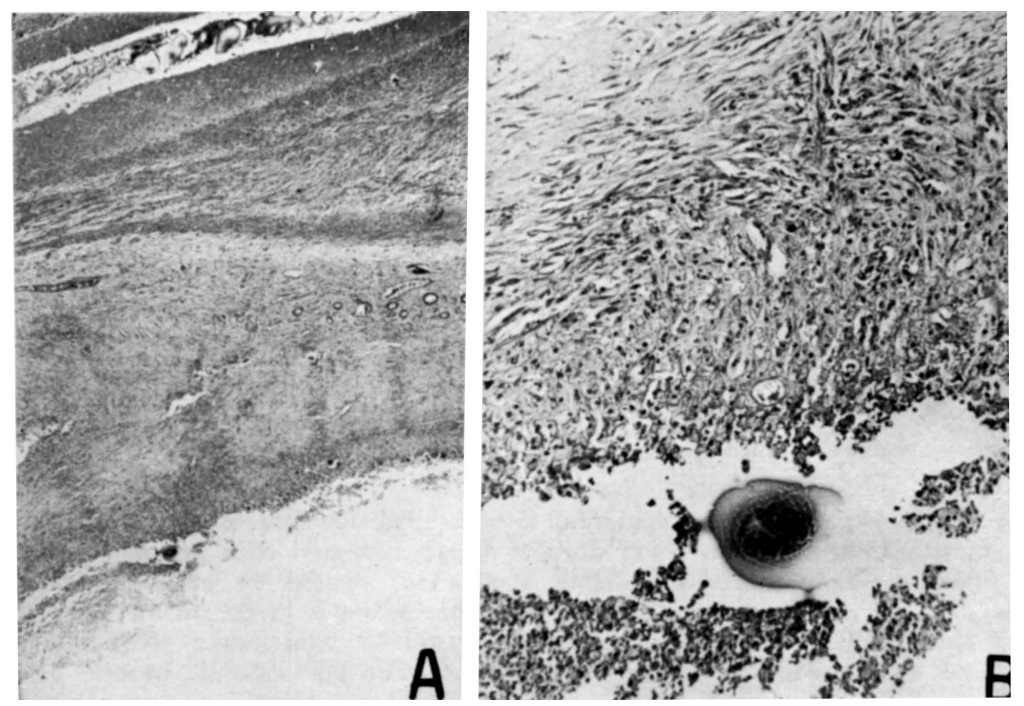

Fig. 2 - Caso E. G. P. Microfotografias do cisto dermóide, mostrando tecidos derivados do ectoderma e mesoderma. $E m$, nota-se um pêlo cortado transversalmente.

sindrome de hipertensão intracraniana e quadro cerebelar instalados dois meses antes da internação. Os exames complementares levaram ao diagnóstico provável de meduloblastoma cerebelar. Foi feita a abertura da lâmina terminal para aliviar a hipertensão intracraniana e, ulteriormente, cobaltoterapia visando a fossa poterior. Com estas medidas houve apenas discreta melhora do quadro de hipertensão intracraniana, não se alterando o quadro ccrebelar. Cogitava-se da intervenção direta na fossa craniana posterior quando ocorreu osteomielite do retalho da craniotomia frontal. O osso contaminado foi retirado, seguindo-se a esta intervenção hipertermia acentuada e convulsões generalizadas, vindo a paciente a falecer. A necropsia mostrou, além de meningite purulenta, a existência de cisto dermóide cerebelar direito, contendo grande quantidade de substância sebácea e alguns pêlos. $O$ exame histopatológico confirmou o diagnóstico microscópico, mostrando tratar-se de tecidos derivados do ectoderma e do mesoderma.

\section{SUMMARY}

Cerebellar dcrmoid cyst. Report of a case.

The authors present a case of cerebellar dermoid cyst, the only one found among the intracranial tumors operated at the Department of Neurolcgy of the Univcrsity of São Paulo Medicine School, betwcen January 1945 and March 1963, thus confirming their rarity. 
A girl 4 years old presented intracranial hypertension plus cerebellar symptons which began two months before admission. The diagnois of meduloblastoma of the vermis based upon the clinical symptons and laboratory findings was made. In accordance to this diagnosis the lamina terminalis was opened and the patient was submitted to a series of cobalt irradiation therapy on the posterior fossa with slight improvement of the neurological picture. Osteomyelites of the bone flap developed with fever and convulsions; 8 days postoperatively the patient died. At necropsy dermoid cyst of right cerebellar hemisfere was found which at the histopathological examination showed tissues from the ectoderm and mesoderm.

\section{REFERÊNCIAS}

1. BROCK, S.; KLEN.KE, D.A. - A case of dermoid overlying the cerebellar vermis. Bull. Neurol. New York 1:328-342 (junho) 1931. 2. CANELAS, H. M.; RICCIARDICRUZ, O.; TENUTO, R. A. - Tumores congênitos do sistema nervoso. Arq. NeuroPsiquiat. (São Paulo) 18:209-223 (setembro) 1960. 3. KEVILLE, F. J.; WISE, B. L. - Intracranial epidermoid and dermoid tumors. J. Neurosurg. 16:565-569 (setembro) 1959. 4. LOVE, J. G.; KERNOHAN, J. W. — Dermoid and epidermoid tumors (cholesteatomas) of central nervous systm. J. A. M. A. 107:1876-1882 (dezembro, 5) 1936.

Clinica Neurológica - Faculdade de Medicina da Universidade de São Paulo Caixa Postal 3461 - Säo Paulo, Brasil. 